\title{
Entre la exculpación y la justificación. Apuntes de legislación comparada latinoamericana sobre pluralismo jurídico y derecho penal*
}

\author{
Myrna Villegas Díaz**
}

\begin{abstract}
RESUMEN
El artículo trata la forma en la que las legislaciones latinoamericanas han abordado la problemática indígena en el área penal, centrándose en las soluciones legales y doctrinales existentes en torno a la responsabilidad penal de indígenas en cuanto son juzgados por derechos penales occidentales. Se describe también, en la medida que guarda relación con los aspectos sustantivos penales que se tratan, la situación del derecho de acceso a la jurisdicción indígena en América Latina concretado en los sistemas jurídicos indígenas existentes en algunos Estados. Se profundiza en eventuales soluciones penales para el indígena que infringe el derecho oficial, tales como la inimputabilidad, el error de probibición y el error de comprensión culturalmente condicionado, finalizando con una toma de postura para abrir un debate.
\end{abstract}

Pluralismo jurídico - derecho penal y pueblos indígenas - error de derecho

\section{Between the excuse and justification. Notes on LatinA merican comparative legislation on legal pluralism and criminal law}

\begin{abstract}
The paper deals with the way in which Latin American legislations have addressed issues related to indigenous people in the area of criminal law, focusing on legal and doctrinal solutions regarding the criminal responsibility of indigenous individuals judged against Western criminal law. It also describes, to the extent that it is related to the substantive issues being addressed, the status of the right of access to justice for indigenous people in Latin America, which is formalised in the legal systems of some States. It explores possible defences for breaches of criminal law by indigenous people, such as insanity, the error of law, and error that is culturally conditioned, and concludes adopting a position to open up the discussion.
\end{abstract}

Legal pluralism - criminal law and indigenous people - error of law

* Este trabajo forma parte del Proyecto Fondecyt Regular № 1110086 "Pluralismo cultural, pueblos originarios y derecho penal chileno: Del derecho indiano a la administración biopolítica. Bases para una reforma penal integral", del que la autora es investigadora responsable.

** Abogada, Doctora en Derecho, Investigadora Centro de Investigaciones Jurídicas, Universidad Central de Chile.mvillegas@ucentral.cl.

Artículo recibido el 28 de febrero de 2012 y aceptado para su publicación por el Comité Editorial el 26 de octubre de 2012. 


\section{INTRODUCCIÓN}

$\mathrm{H}$ ace setenta años Medrano Ossio afirmó, en una ponencia presentada al Segundo Congreso Latinoamericano de Criminología (Santiago de Chile, enero 1941), y cuya publicación fue prologada por Jiménez de Asúa, que el indígena debía ser declarado "un ser únicamente peligroso" y no responsable penalmente, debido a que su "estado psicológico-mental y la especial situación que ocupa dentro de la sociedad no se corresponden con esa injusta y anticientífica responsabilidad que le impone el derecho penal". El indígena, a su juicio, era un inimputable, porque "no se da cuenta ni forma conciencia de los verdaderos alcances del acto delictuoso que ha realizado", siendo preciso "el establecimiento de entidades técnicas especializadas ya para el juzgamiento, ya para la aplicación de medidas de seguridad para inocuizarlo (por su peligrosidad) o adaptarlo a la sociedad" .

Ya desde el positivismo criminológico reinante de los años 40 se asumía que al indígena juzgado por el derecho oficial debía tratársele de una manera distinta, la pregunta a responder es si esta es la forma adecuada o si existen otros tipos de soluciones más acordes con derechos fundamentales. A tales efectos, el presente artículo ofrece de manera sistematizada la forma por la cual las legislaciones penales latinoamericanas han abordado la responsabilidad penal del indígena, tanto en sus aspectos sustantivos penales como procesales, centrados en el derecho oficial. No se hará referencia en esta oportunidad al "derecho penal indígena", esto es, la forma en la que desde su "derecho propio" los indígenas resuelven sus problemas de relevancia penal ${ }^{2}$.

En general es posible diferenciar dos grandes posturas: liberales y comunitaristas ${ }^{3}$. Posturas liberales sostienen que el indígena debe ser integrado a un cuerpo social, en un Estado que garantiza los mismos derechos para todos. Puede tratarse de un liberalismo ciego a la diferencia y defensor de la neutralidad del Estado ante el problema como el de Kymlicka ${ }^{4}$ que pudiera conducir a justificar una homogeneización del cuerpo social; o un liberalismo defensor del "respeto igualitario" muy parecido al comunitarismo (Charles Taylor ${ }^{5}$ ) que reconoce la diferencia permitiendo que los objetivos de un grupo cultural en particular puedan cumplirse ${ }^{6}$, sea mediante un reconocimiento legal, o mediante una privatización de la diferencia ${ }^{7}$. Las posturas comunitaristas reconocen que la identidad

${ }^{1}$ Medrano Ossio, J. "Responsabilidad penal de los indígenas", Cuadernos Universidad Autónoma Tomás Frías, Potosí, Bolivia, 1940, pp. 19 y 36.

2 Término usado por Borja, E. Introducción a los fundamentos del Derecho Penal Indígena, Edit. Tirant Lo Blanch, Monografías, Valencia, 2001.

${ }^{3}$ Sobre el punto, ampliamente, Carnevalli, R. "El multiculturalismo: un desafío para el derecho penal moderno”. En Rev. Política Criminal, N ${ }^{\circ}$ 3, 2007. Disponible en www.politicacriminal.cl (fecha consulta: 25-01-2012).

${ }^{4}$ Kymlicka, W., Edit. Ciudadanía multicultural Paidós: Estado y Sociedad. Barcelona, 2006.

5 Taylor, Ch. "La política del reconocimiento", en Taylor, Ch., Gutmann, A., Habermas, J. El multiculturalismo y "la política del reconocimiento", FCE, 2a . Edic. (español), México, 2009, pp. 53-116, esp. p. 101.

${ }^{6}$ Véase Comentario de Steven Rockefeller al artículo de Taylor, Ch. ob. cit., p. 136.

${ }^{7}$ Barry, B. Culture and Equality. An Egalitarian critique of Multiculturalism, Harvard University Press, 2002. Un excelente análisis sobre las posturas de este autor en Villavicencio, L. "Privatizando la diferencia: El 
del individuo está referida a un contexto cultural, por lo que el Estado debe defender aquellas culturas que tienen dificultades para subsistir como tales, como los indígenas ${ }^{8}$. Comunitaristas radicales defienden la existencia de unidades culturales capaces de sobrevivir aisladamente, como culturas dominadas por una cultura dominante, idea que ha sido criticada, entre otros, por Touraine?

Partiremos aquí de la idea de pluralismo jurídico, entendido como la posibilidad de coexistencia de culturas en un mismo territorio desde una perspectiva intercultural ${ }^{10}$, entendiendo, junto con Zaffaroni que la integración en un Estado pluricultural no puede significar el sacrificio de una de las culturas ${ }^{11}$.Luego, la política pública en materia indígena no puede ser "monocultural", sino, a lo menos "consultiva" de conformidad con el Convenio $169^{12}$ contemplando la posibilidad de "darles acceso a los miembros de los pueblos al ejercicio del poder público" ${ }^{13}$.

\section{ReCONOCIMIENTO CONSTITUCIONAL A DERECHOS DE LOS PUEBLOS INDÍGENAS Y SU IMPLICANCIA EN EL DERECHO PENAL}

La mayoría de los países latinoamericanos con presencia indígena, a excepción de Chile, contemplan el reconocimiento constitucional a la diversidad cultural, muchos de ellos de manera específica a pueblos originarios. Asimismo han ratificado el Convenio 169

liberalismo igualitario y el pluralismo cultural", Revista de Derecho, Universidad Austral de Chile, Vol. XXIII, $\mathrm{N}^{\circ}$ 1, julio 2010, pp. 37-57.

${ }^{8}$ Carnevalli, R. ob. cit., p. 14, citando a Walzer.

${ }^{9}$ Touraine ha sostenido que es precisamente esta forma de abordar el problema indígena lo que condujo al fracaso de los movimientos políticos indigenistas en América andina, desde que "quisieron poner en pie un movimiento político de defensa de las culturas indígenas, cuando en realidad es urgente que las poblaciones indias puedan manejar dentro de instituciones democráticas sus intereses culturales y económicos" Touraine, A. ¿Podemos vivir juntos? , FCE, D.F. México, 1997, p. 174.

${ }^{10}$ En este sentido aludimos al pluralismo jurídico emancipador, donde todavía se buscan soluciones dentro del derecho oficial (ej. Vía causales de justificación y/o exculpación basadas en la diversidad cultural), pluralismo emancipador que es antesala de la legalidad alternativa y que se refiere a la coexistencia de ordenamientos jurídicos paralelos que responden a los distintos derechos producidos y aplicados provenientes de "las luchas y prácticas sociales comunitarias, independientes del favor de los órganos o agencias del Estado. Ampliamente Wolkmer, C.: "Pluralismo Jurídico: nuevo marco emancipatorio en América Latina". En García Villegas, M., Rodríguez, C. (Eds.). Derecho y sociedad en América Latina: Un debate sobre los estudios jurídicos críticos, Ilsa, Universidad Nacional de Colombia, 2003, pp. 247 a 259, pp. 250 y ss.

${ }^{11}$ Entrevista escrita a Raúl Zaffaroni, profesor emérito de la Universidad de Buenos Aires, miembro de la Corte Suprema de Justicia Argentina, redactor del Anteproyecto de Código Penal boliviano. Stgo. Chile. Buenos Aires, 15 julio 2011.

${ }^{12}$ Entrevista escrita a Raúl Zaffaroni, profesor emérito de la Univ. de Buenos Aires, miembro de la Corte Suprema de Justicia Argentina, redactor del Anteproyecto de Código Penal boliviano. Stgo. Chile - Buenos Aires, 15 julio 2011. Entrevista a Jorge Vicente Paladines. Profesor de Criminología y sistemas penales de la Univ. Andina Simón Bolívar en Ecuador. Ciudad de Guatemala, 14 abril 2011.

${ }^{13}$ Entrevista a Carlos Loarca, Defensor indígena, asesor de comunidades mayas en Guatemala, consultor de organizaciones indígenas, Ciudad de Guatemala, 13 abril 2011. 
y contemplan reconocimiento penal expreso a los derechos de los indígenas ${ }^{14}$. Respecto de la forma de abordar este reconocimiento, siguiendo a Tully y Bonilla ${ }^{15}$, pensamos que los planteamientos liberales y comunitaristas comparten ciertas características estructurales que impiden reconocer - a lo menos adecuadamente- la diversidad cultural. Esto porque se trata de un "reconocimiento" a la diversidad en una Constitución hecha por la cultura dominante, una Constitución que expresa normativamente el "Ser" de una comunidad política de origen occidental ${ }^{16}$.

Ahora bien, si "la cultura es un elemento irreductible de la política"17, no existe razón para no considerar a las distintas culturas que conforman la comunidad política en los procesos de elaboración de las Constituciones. Se trata de alcanzar un diálogo constitucional intercultural de manera tal que pudiera darse lugar a una Constitución multicultural, como ideal a alcanzar. Esto requiere, claro está, dar atención a ciertos aspectos históricos del constitucionalismo moderno así como a sus limitaciones ${ }^{18}$, entre ellas la identificación del concepto de soberanía popular con un grupo culturalmente homogéneo, y cuyo tratamiento excede el objeto de este artículo.

No obstante este ideal a alcanzar, en este trabajo y para el análisis penal que sigue reconoce la existencia de constituciones monoculturales. Consciente de la contradicción que implica la defensa del pluralismo jurídico versus soluciones buscadas dentro de una estructura jurídica dominante ${ }^{19}$, adscribo a la idea del reconocimiento normativo de los derechos de los pueblos indígenas en las cartas Fundamentales, como paso importante en el camino a la consideración de la diferencia, dejando atrás la idea de un principio de igualdad basado en la uniformidad. En este sentido, el reconocimiento constitucional a los derechos de los pueblos originarios es expresión del principio democrático: el gobierno de las mayorías con pleno respeto a las minorías ${ }^{20}$.

La relevancia penal del reconocimiento constitucional queda de manifiesto muy especialmente en aquellos casos en los que hay órdenes jurídicos paralelos al oficial,

${ }^{14}$ Un trabajo preliminar se encuentra en Valenzuela, M. "Derechos de los pueblos indígenas en el contexto internacional, especialmente en lo relativo a los aspectos penales”, Revista de Estudios Criminológicos y Penitenciarios, $\mathrm{N}^{\circ}$ 6, Santiago de Chile, 2003, pp. 9-36.

15 Tully, J. Strange Multiplicity. Constitucionalism in an Age of Diversity/Extraña multiplicidad. El constitucionalismo en una era de diversidad. Cambridge University Press, UK, 1997 y Bonilla, D. La Constitución multicultural, Siglo del Hombre Editores, Colombia, 2006.

16 Aldunate, E. "Interpretación constitucional y decisión política”, Revista de Derecho, Universidad Católica de Valparaíso, N XV, 1993-1994, pp. 31-65. Le sigue Carmona, C. "Derecho y Violencia: reescrituras en torno al pluralismo jurídico", Revista de Derecho, Universidad Austral de Chile, Vol. XXII N ${ }^{\circ}$, diciembre 2009, pp. 9-26, esp. p. 13.

${ }^{17}$ Bonilla, D. ob. cit., p. 81

${ }^{18}$ En ello cabe destacar tres movimientos políticos diferentes que lucharon por el reconocimiento al otro: la creación de las naciones Estado que siguieron a la oposición al sacro Imperio Romano, la emancipación política de las colonias hasta llegar a la política del reconocimiento. Ampliamente, Bonilla, D. ob. cit., pp. 80 y ss.

${ }^{19}$ Carmona, C. ob. cit., p. 13

${ }^{20}$ Cabedo, V. Constitucionalismo y Derecho Indígena en América Latina, Editorial Universidad Politécnica de Valencia, Colección Amadís, Valencia, 2004, p. 91. 
porque significa, por un lado, que el derecho consuetudinario indígena pasa a ser fuente de derecho penal, desde que incrimina ciertas conductas y les asocia una pena; y por el otro lado, la admisión de una jurisdicción especial a cargo de autoridades indígenas que debe ser coordinada legalmente con la jurisdicción oficial y que se ejerce en un determinado ámbito territorial ${ }^{21}$. En aquellos casos, como el nuestro, en que no existe sanción (aprobación) constitucional de los derechos de los pueblos indígenas, deben articularse complejos entramados jurídicos sobre la base de tratados internacionales para justificar soluciones penales que puedan ir más allá de un escueto reconocimiento a las costumbres indígenas como meros antecedentes para la consideración de circunstancias eximentes o atenuantes de responsabilidad penal, esto es, un reconocimiento casi "periférico" 22 de la diversidad. Sobre esto volveremos al tratar el caso chileno.

\section{RECONOCIMIENTO PENAL A LOS DERECHOS DE LOS INDÍGENAS EN LA LEGISLACIÓN COMPARADA LATINOAMERICANA}

Desde el punto de vista sustantivo penal, las soluciones del derecho occidental latinoamericano se inclinan por conceder al indígena una causal de exculpación en aquellos casos en los que comete un hecho punible en la legislación penal del Estado, pero obedeciendo a su cultura, ya sea considerándole como inimputable (ej. Colombia), o que ha actuado bajo un error de prohibición (ej. Perú $)^{23}$. En los aspectos adjetivos encontramos sistemas en los que existe un único orden jurídico a nivel nacional, que contempla, con mayor o menor énfasis, un reconocimiento penal a los derechos de pueblos indígenas; así como a sistemas mixtos en los que existe un orden jurídico nacional, y sistemas jurídicos diferenciados para indígenas que viven en comunidades.

\section{América del Norte: México}

La Constitución Federal mexicana reconoció por primera vez a los pueblos indígenas en 1992, para luego ir ampliando este reconocimiento mediante reformas ${ }^{24}$. En cuanto a la legislación penal sustantiva, el reconocimiento se plasma según el instrumento de que se trate, pudiendo distinguirse el Código Penal Federal, las Leyes Federales y los Códigos Penales estatales.

${ }^{21}$ Hurtado Pozo, J. "Derecho Penal y Diferencias culturales: el caso peruano", en Borja, E. (coord.) Diversidad cultural: conflicto y derecho, Tirant Monografías, Valencia, 2006, pp. 373-388, p. 385.

${ }^{22}$ Carmona, C. ob. cit., p. 14.

${ }^{23}$ Modolell, J.L. "Breves consideraciones sobre la posible responsabilidad penal de sujetos pertenecientes a grupos culturalmente diferenciados (casos del indígena y costumbres de origen afroamericano), en Derecho Penal y Pluralidad Cultural, Anuario de Derecho Penal, 2006, pp. 273-286.

${ }^{24}$ Aragón, O. "Los sistemas jurídicos indígenas frente al derecho estatal en México. Una defensa del pluralismo jurídico”. Boletín Mexicano de Derecho Comparado, Nueva serie, XL (118), 2007, pp. 9-26, esp, p. 11. 
El Código Penal Federal contiene normas comunes para todos los habitantes del territorio mexicano sin que se contenga norma especial de reconocimiento penal a la diversidad cultural mediante alguna cláusula de exclusión de la antijuridicidad y/o culpabilidad (art. 1 con relación al art. 15). La inimputabilidad y el error de prohibición están establecidos con carácter general. Sin embargo existen normas específicas que obligan a considerar para la determinación de penas y/o medidas de seguridad, entre otros, la calidad de indígena del sujeto, los usos y costumbres de los pueblos o comunidades a que pertenezcan (arts. 51 y 52 del CPF). Así también se contempla norma especial respecto de la tenencia de cierto tipo de narcóticos (peyote u hongos alucinógenos) cuando pueda presumirse que serán utilizados en ceremonias de conformidad con usos y costumbres indígenas, caso en el cual el Ministerio Público no puede iniciar persecución penal (art. 195 bis. II del CP Federal).

Existen también algunas normas específicas en Leyes Federales. Así por ejemplo, la ley para prevenir y sancionar la trata de personas: prevé una agravación de pena en el delito de trata de personas cuando los "tratados" son indígenas (art. 6). La ley para el Tratamiento de Menores Infractores, para el Distrito Federal en materia común y para toda la República en materia Federal prevé normas especiales para menores indígenas ${ }^{25}$. La mayoría de los Códigos Penales estatales también contienen una norma especial similar a la del Código Federal respecto de la determinación y aplicación de penas y/o medidas de seguridad ${ }^{26}$. Mas ninguno de ellos contempla la posibilidad de exclusión de responsabilidad. Resulta interesante otra normativa específica contenida en el CP de Veracruz que reconoce los usos y costumbres indígenas como límite al ius puniendi (art. 3), así como una excepción a la aplicación de la ley penal en cuanto a las personas cuando se tratare de indígenas (art.15).

Por último existen las Leyes Federales emitidas por algunos estados para abordar ciertas materias específicas en las que se considera la calidad de indígena. Así por ejemplo, en los estados del Distrito Federal Durango y Puebla la ley de menores y adolescentes contempla normas similares a las del Código Penal Federal ${ }^{27}$. En los estados de Jalisco y Chiapas existen leyes sobre ejecución de penas que contemplan en su normativa expresamente la calidad de indígena para la aplicación de las mismas ${ }^{28}$.

${ }^{25}$ Así p.ej. los menores indígenas tienen derecho a ser asistidos por intérpretes y defensores que tengan conocimiento de su lengua y cultura. (arts. 3, 21.VI, 32.IV y 36 inc. final), que el Consejo de Menores, al aplicar las disposiciones de la ley deberá tomar en cuenta los usos y costumbres de los pueblos o comunidades a que pertenezcan (art. 5).

${ }^{26}$ Así p.ej. art. 71.V del CP de Chiapas, art. 74.VI del CP de Yucatán, art. 84 del CP de Veracruz, art. 56 CP del CP de Tabasco; art. 57.V del CP de Sonora; art. 75.V CP de Sinaloa; art. 47.V del CP de Nuevo León, art. 65.IV c) CP de Nayarit, arts. 32 y 58 del CP de Morelos, art. 54.V del CP de Michoacán; art. 57.V del CP de México; art. 41.II del CP de Jalisco; art. 92.V del CP de Hidalgo; arts. 79. V y 82 del CP de Durango; art. 72.V del CP del Distrito Federal; art. 64.II del CP de Colima; art. 67.V del CP de Chiguagua; art. 81.II del CP de Baja California Sur.

${ }^{27}$ Arts. 11.VIII, 58.V, 115 inciso final de la Ley de Justicia para adolescentes para el Distrito Federal, Arts. 15.II, 18, 28, 113, 296 del Código de Justicia para Menores Infractores en el Estado de Durango; Arts. 138, 210, 273.II de la Ley de Justicia para adolescentes del Estado de Puebla.

${ }^{28}$ Ley de Ejecución de penas del Estado de Jalisco (arts. 22 y 63); Arts. 27. XIV y 8 del Código de Ejecución de Sanciones Penales y Medidas de Libertad Anticipada para el estado de Chiapas. 


\section{Centroamérica y América del Sur}

\subsection{Guatemala}

Treinta y seis años de conflicto armado y la violencia contrainsurgente de los años ochenta trajo como consecuencia, entre otros, que una generación completa de líderes indígenas fuera asesinada ${ }^{29}$. Los Acuerdos de Paz de 1996 firmados entre el Gobierno y los guerrilleros, la mayoría de los cuales eran mayas, garantizaron, entre otros, los derechos de los indígenas y una reforma de las tierras ${ }^{30}$ y un respaldo a políticas multiculturales, particularmente al Acuerdo sobre Identidad y Derechos de los Pueblos Indígenas (1995) ${ }^{31}$. A pesar de estos acuerdos y de que los indígenas en Guatemala constituyen aproximadamente el $50 \%$ de la población ${ }^{32}$, lo que supondría una legislación indígena a lo menos sistematizada, si bien existe un reconocimiento constitucional ${ }^{33}$ (art. 66 Constitución de Guatemala de 1985) ${ }^{34}$, la legislación relativa a los mismos se encuentra dispersa y desordenada.

Esto parece obedecer a una marcada resistencia de la población mestiza guatemalteca, desde su independencia, a reconocer jurídicamente cualquier derecho a los indígenas ${ }^{35}$, lo que ha llevado a reconocimientos culturales que han sido calificados por el movimiento indigenista como "un multiculturalismo cosmético" y "neoliberal" 36 . Con motivo de la ratificación del Convenio 169 de la OIT (1997) se intentó una reforma constitucional para reconocer el derecho consuetudinario de los indígenas, que fue rechazada por referéndum popular en 1999. Desde 2000 en adelante se parecían esfuerzos de comunidades mayas por consolidar y/o fortalecer su derecho ${ }^{37}$.

El Código Penal no contiene ninguna norma específica que permita la exculpación o justificación de indígenas cuando infringen el derecho occidental, así como tampoco el error de prohibición (para todos los casos) ${ }^{38}$. Sí se contempla una atenuación de

29 Sieder, R, Flores, C. Autoridad, autonomía y derecho indígena en la Guatemala de posguerra. F \& G Editores, Casa Comal, Universidad Autónoma de Morelos, Guatemala, 2011, p. 14.

${ }^{30}$ Bou Franch, V. "En busca de un estatuto jurídico para los pueblos indígenas”, en Borja, E. (coord.) Diversidad cultural: conflicto y derecho, Tirant Monografías 419, Valencia, 2006, pp. 103-160, p. 116.

31 Sieder, R., Flores, C., ob. cit., p. 15.

32 Sieder, R., Flores, C., ob. cit., p. 15, nota 1.

${ }^{33}$ El primer reconocimiento constitucional lo hizo la Constitución de 1945, en medio de una violenta polémica entre conservadores e indigenistas. Ampliamente García. J.M. El estatuto indígena en la Constitución Guatemalteca de 1945. Edit. Serviprensa, Guatemala, 2010, pp. 43, 52 y 75.

34 Art. 66 Constitución Política: "Guatemala está formada por diversos grupos étnicos entre los que figuran indígenas de ascendencia maya. El Estado reconoce, respeta y promueve sus formas de vida, costumbres, tradiciones, formas de organización social, el uso del traje indígena en hombres y mujeres, idiomas y dialectos".

${ }^{35}$ Bou Franch, V., ob. cit., p. 116.

36 Sieder, F. Flores, C., ob. cit., p. 16.

${ }^{37}$ Sieder, R., Flores, C., ob. cit., p 21.

38 Ampliamente Baquiax, J. "Error de prohibición culturalmente condicionado como causa de inculpabilidad”. Tesis de Máster en Derecho Penal. Universidad de Sevilla. España, 2009, sin publicar. 
responsabilidad para los casos de ignorancia cuando esta ha influido en la ejecución del delito (art. 26 Núm. 9 CP) ${ }^{39}$. Mediante Decreto 57-2002 se modificó el CP con el fin de sancionar la discriminación o el impedimento, entre otros, al ejercicio del derecho consuetudinario o costumbre. Establece también una agravante por motivos discriminatorios. Esta figura fue criticada por organizaciones indígenas y la Corte Interamericana de Derechos Humanos ${ }^{40}$.

En cuanto a los aspectos procesales, existe un único ordenamiento legal nacional que se compone de la Constitución y las leyes ordinarias, entre ellas la procesal penal. No existe una ley sobre jurisdicción indígena, pero a los mayas y otras comunidades indígenas se les da el derecho de autonomía municipal de conformidad con su derecho consuetudinario ${ }^{41}$. Las autoridades judiciales indígenas resuelven conflictos, también los de relevancia penal aplicando sanciones ya sea según el derecho consuetudinario maya como las que imponga el pleno de una Asamblea Comunitaria. Las instituciones a las cuales recurren los indígenas no son tribunales, sino Consejos de Ancianos, Alcaldías Indígenas, Comités comunitarios, y la asamblea comunitaria, siendo la Alcaldía Indígena el lugar que más frecuentan ${ }^{42}$. Las resoluciones deberían ser vinculantes para la justicia oficial, pero como ha revelado un experto "son vinculantes en la medida que el operador de justicia considere que no toca los intereses principales de la justicia oficial y en cuanto no toque los intereses de los terratenientes que puedan tener una marcada influencia en el Estado" 43.

Otra institución que resuelve conflictos indígenas de relevancia penal y que se encuentra incorporada en la estructura del organismo judicial son los Juzgados de Paz Comunitarios (arts. 58,101y 102 de la Ley del Organismo judicial) que operan desde 1997 y que se integran por tres miembros de las comunidades y aplican el derecho consuetudinario, el que se reconoce en la medida que no vaya contra la Constitución ni los tratados internacionales sobre derechos humanos. A 2012 hay 6 juzgados de paz comunitarios. Esta consagración no necesariamente implica el reconocimiento del derecho indígena, pues "la legislación nacional faculta al Tribunal de Paz Comunitario para resolver los conflictos con arreglo a los usos y costumbres, la equidad y los principios generales del derecho cuando ello fuera posible, lo cual otorga al tribunal la posibilidad de decidir sin considerar el derecho consuetudinario indígena" ${ }^{4}$.

${ }^{39}$ Ídem, p. 38.

${ }^{40}$ Según la CIDH en su informe de 2003 que se trata de "una norma de carácter general, que no consideró adecuadamente la especificidad de los pueblos indígenas y no estableció mecanismos y medidas para evitar el racismo que se produce en Guatemala contra los mayas, garífunas y xincas. La Comisión considera que la norma penal establecida en el Código Penal no refleja todos los motivos de discriminación prohibidos por el artículo 1 de la Convención Americana". Asimismo la CIDH considera que "el texto de esta norma penal debió realizarse previa consulta a los pueblos indígenas en Guatemala”.

${ }^{41}$ Bou Franch, V. ob. cit., p. 117.

42 Instituto de la Defensa Pública Penal Guatemalteca. Proyecto "Defensorías Indígenas. Peritajes culturales y su aplicación en la Administración de Justicia”, Guatemala, 2009, p. 9.

${ }^{43}$ Entrevista a Carlos Loarca, Defensor indígena, asesor de comunidades mayas en Guatemala, consultor de organizaciones indígenas, Ciudad de Guatemala, 13 abril 2011.

${ }^{44}$ Informe CIDH 2003. 


\subsection{Colombia}

La Constitución colombiana de 1991 reconoce la diversidad étnica y cultural de la nación colombiana (art. 7) al mismo tiempo que el derecho a la jurisdicción indígena (art. 246). En cuanto a los aspectos de Derecho Penal Sustantivo, el Código Penal Nacional contiene algunas normas que consideran la diversidad indígena. La más importante es aquella que establece como causal de inimputabilidad, la no comprensión de la ilicitud de la conducta o de determinarse de acuerdo con esa comprensión, por diversidad sociocultural (art. $33 \mathrm{CP})^{45}$, es decir, la irresponsabilidad penal del indígena se establece vía causal de exculpación. Esta norma que data del CP de 1936 consideró en un primer momento al indígena inimputable en virtud de determinadas condiciones psicosociales desde que pertenecía a una comunidad, y que le impedía comprender la ilicitud de la conducta, luego mutó a la imposibilidad de comprender esta ilicitud por diversidad sociocultural ${ }^{46}$.

Así también, en el Código Penal existe un mandato expreso en orden al tipo de medidas de seguridad aplicables a indígenas declarados inimputables por diversidad sociocultural, las que deberán consistir en la reintegración a su medio cultural (art. 73). En concordancia con esta disposición el Código de Procedimiento Penal ordena a los jueces de ejecución de penas y medidas de seguridad coordinarse con la autoridad indígena de la comunidad respectiva para la ejecución de la misma (art. 470 CPP).

En cuanto al derecho penal adjetivo, por mandato constitucional, podemos distinguir dos jurisdicciones paralelas: de un lado, el sistema jurídico nacional, que se compone de: a) la Constitución Política y la legislación nacional, que se aplica a los indígenas en cuanto son considerados "ciudadanos" colombianos; y b) la legislación indígena nacional, que ha sido asumida por aquellos pueblos indígenas andinos y comunidades indígenas que, a consecuencia del proceso de aculturación, han perdido sus costumbres ancestrales en forma total o parcial, sus sistemas de control y de autoridades, y que se encuentran en proceso de recuperación de sus sistemas normativos propios ${ }^{47}$. De otro lado, están los sistemas jurídicos indígenas, sistemas propios que tienen jurisdicción legal por reconocimiento constitucional, y que cuentan con autoridades propias, sistemas de control y órganos decisorios.

El fundamento legal de este sistema "mixto" se encuentra en el art. 30 del Código de Procedimiento Penal que exceptúa de la jurisdicción penal ordinaria a los asuntos de los cuales conozca la jurisdicción indígena. De conformidad con esta norma el art. 12 de la ley 270 de 1996, dispone que: ... Las autoridades de los territorios indígenas previstas en la

45 Artículo 33 CP. Inimputabilidad. Es inimputable quien en el momento de ejecutar la conducta típica y antijurídica no tuviere la capacidad de comprender su ilicitud o de determinarse de acuerdo con esa comprensión, por inmadurez sicológica, trastorno mental, diversidad sociocultural o estados similares.

${ }^{46}$ Becerra, C. "La jurisdicción especial indígena y el derecho penal en Colombia: Entre el pluralismo jurídico y la autonomía relativa”. El Otro Derecho, No 35, 2006, pp. 213-236, p. 219.

${ }^{47}$ Cabedo, V. La Jurisdicción Especial Indígena de Colombia y los Derechos Humanos, Valencia, 30 diciembre de 1998. http://www.alertanet.org/F2b-VCabedo.htm (fecha consulta: 02-03-2012). 
ley ejercen sus funciones jurisdiccionales únicamente dentro del ámbito de su territorio y conforme a sus propias normas y procedimientos, los cuales no podrán ser contrarios a la Constitución y a las leyes. Estas últimas establecerán las autoridades que ejercen el control de Constitucionalidad y legalidad de los actos proferidos por las autoridades de los territorios indígenas...

Algunas de las cuestiones que han suscitado polémica en el sistema colombiano es la posibilidad de juzgamiento de indígenas en el sistema nacional, cuestión que ha sido interpretada por algunos autores como una incongruencia (pues entonces no se justifica la jurisdicción especial indígena si en algunos casos no pueden ser juzgados por sus autoridades $)^{48}$. A la inversa, se considera también incongruente que cuando una persona no indígena comete delito en territorio indígena, afectando a uno o más de sus miembros o a la comunidad, el Estado reclame jurisdicción impidiendo a esa comunidad juzgarlo ${ }^{49}$.

\subsection{Ecuador}

La Constitución ecuatoriana de 2008 también reconoce la diversidad cultural y las jurisdicciones indígenas, consagrando en primer lugar el principio de ne bis in idem considerando los casos resueltos por la justicia indígena (art. 76.7 letra i). La justicia indígena se consagra sobre la base de derechos territoriales y personales, atendiendo en especial a la participación de la mujer indígena (Art. 171 C.E).

El Código Penal ecuatoriano no contiene ningún reconocimiento a la especificidad indígena. No obstante existe un proyecto de Código Orgánico Integral Penal (COIP) ${ }^{50}$ que ha sido presentado para discusión a la Asamblea Nacional que abandona las infracciones cometidas dentro de una comunidad indígena, a la dictación de una ley especial, pero excluye de la jurisdicción indígena a los adolescentes indígenas que cometan infracciones dentro de sus comunidades, los que serán juzgados de conformidad con la ley penal adolescente nacional (art. 1).

La ausencia de normativa expresa que reconozca la diversidad cultural en el Código penal ecuatoriano es vista como una falencia, alzándose voces en favor de una reforma sustantiva penal que tome una visión multicultural. "Hay que entender ese diálogo intercultural que nos hace observar que en una comunidad indígena... esa comprensión

\footnotetext{
${ }^{48}$ Becerra, C., ob. cit., pp. 215, 223.
}

${ }^{49}$ Londoño, H. "El fuero y la jurisdicción penal especial indígenas en Colombia”. En Derecho Penal y pluralidad cultural, Anuario de Derecho Penal, pp. 153-210, 2006, p. 182.

${ }^{50} \mathrm{El}$ antecedente de este proyecto es el Anteproyecto de Código Orgánico de Garantías Penales que establecía principios fundamentales de la jurisdicción indígena en el ámbito penal, entre otros el reconocimiento de autoridades, procedimientos y resolución de conflictos penales conforme al derecho propio de las comunidades, pueblos y nacionalidades indígenas y en los que la justicia ordinaria no puede interferir, teniendo como límite los derechos humanos. Así también, la consagración de principios de diversidad, igualdad, ne bis in ídem, interpretación pro jurisdicción indígena e intercultural, máxima autonomía y mínima intervención estatal, así como del error de comprensión culturalmente condicionado. Ministerio de Justicia y Derechos Humanos. Anteproyecto de Código Orgánico de Garantías Penales. La Constitucionalización del Derecho Penal. Publicación de la Serie Justicia y Derechos Humanos, Neoconstitucionalismo y Sociedad, V\&M Gráficas, Quito, Ecuador, 2009. 
de ilicitud es distinta a la que puede suceder... en la justicia ordinaria o en la visión noroccidental. Por ejemplo la sanción que se pueda dar mediante la ortiga, el baño en agua helada, la exposición pública del desnudo de las personas procesadas de las comunidades indígenas creo que es una forma de poder resolver su conflicto desde su visión..." 51 . Por eso es que en la opinión de expertos resulta conveniente una solución como la del error de comprensión culturalmente condicionado, sustituyendo la vieja distinción entre error de hecho y error de derecho que contiene el CP ecuatoriano ${ }^{52}$.

La jurisdicción indígena está reconocida territorialmente para sus comunidades, cuyas autoridades conocen y juzgan conflictos penales que en ellas se produzcan, conforme a su derecho propio o consuetudinario ${ }^{53}$. Los problemas que se originan vienen determinados en primer lugar por la imposibilidad de extender la competencia fuera de sus territorios. Por ejemplo, si se comete un delito entre indígenas, pero fuera del territorio de su comunidad, se juzga por la ley nacional. Lo mismo si un mestizo comete delito en territorio indígena. Esto constituye en la actualidad el gran debate legislativo, alzándose voces para que en casos como el último, se someta a la voluntad del propio sujeto activo la posibilidad de ser juzgado por la comunidad indígena donde delinque o por la justicia ordinaria, pues en algunos casos la pena de la justicia comunitaria, aun consistiendo en castigo físico, parece ser menos gravosa que la de la ley oficial. Otro problema es que, aunque no existe prohibición constitucional, los delitos que pueden conocer las comunidades indígenas son menores, p. ej., no puede conocer de un homicidio calificado en serie, tampoco de narcotráfico ${ }^{54}$.

\subsection{Perú}

La Constitución peruana reconoce en su art. 2, dentro de los derechos fundamentales de las personas, el derecho "A su identidad étnica y cultural. El Estado reconoce y protege la pluralidad étnica y cultural de la Nación”. "Todo peruano tiene derecho a usar su propio idioma ante cualquier autoridad mediante un intérprete. Los extranjeros tienen este mismo derecho cuando son citados por cualquier autoridad. (Art. 2 núm. 19). Reconoce a las “comunidades nativas” en cuanto personas jurídicas (art. 89). Así también en su art. 149 reconoce la jurisdicción indígena.

El Código Penal peruano reconoce en su art. 15 el error de comprensión culturalmente condicionado, en los siguientes términos: "El que por su cultura o costumbres comete

${ }^{51}$ Entrevista a Jorge Vicente Paladines. Profesor de Criminología y sistemas penales de la Universidad Andina Simón Bolívar en Ecuador. Ciudad de Guatemala, 14 abril 2011.

52 Ídem.

53 Un buen análisis penal sustantivo sobre la justicia indígena en los Andes ecuatorianos en Borja, E. Introducción a los fundamentos del derecho penal indígena, Tirant Monografías, Valencia, 2001. Trabajo que continúa luego en "Sobre los ordenamientos sancionadores originarios de Latinoamérica". En Derecho Penal y pluralidad cultural. Anuario de Derecho Penal 2006, pp. 101-151; y en "Derecho indígena sancionador y derechos humanos”, en Giraudo, L. (Ed.), ob. cit., 2008, pp. 185-213.

${ }^{54}$ Entrevista a Jorge Vicente Paladines. Profesor de Criminología y sistemas penales de la Universidad Andina Simón Bolívar en Ecuador. Ciudad de Guatemala, 14-04-2011. 
un hecho punible sin poder comprender el carácter delictuoso de su acto o determinarse de acuerdo a esa comprensión, será eximido de responsabilidad. Cuando por igual razón esa posibilidad se halla disminuida, se atenuará la pena”. Pese a que el mismo Código penal declara que se trata de un error de comprensión culturalmente condicionado, la redacción de esta norma ha dado lugar a interpretaciones. Hurtado Pozo sostiene que se trataría de una forma de error de prohibición, igual al contemplado en el art. 14 del mismo CP, pues consiste en una "incapacidad" de comprender el carácter delictuoso del acto o de autodeterminarse según esta apreciación por razones de cultura o de costumbre $^{55}$. También se protege, mediante figuras agravadas, delitos que se cometan contra el medio ambiente al interior de tierras de comunidades nativas o campesinas o pueblos indígenas (arts. $309 \mathrm{~N}^{\circ} 2$ y $310 \mathrm{C} \mathrm{N}^{\circ} 1 \mathrm{CP}$ ).

En cuanto al ejercicio de su derecho a la jurisdicción, el Art.149 de la Constitución peruana "faculta" a las comunidades y pueblos indígenas para aplicar su derecho consuetudinario, o las normas y procedimientos propios, teniendo como límites la constitución y las leyes ${ }^{56}$. Esta aplicación es en las comunidades nativas distinta de las andinas, estas últimas más integradas y asimiladas, de manera tal que en los conflictos más graves (ej. homicidios) se suele recurrir a la justicia oficial ${ }^{57}$. Las comunidades andinas se rigen por la Ley de Comunidades campesinas ( $\mathrm{N}^{\circ} 24656$ de 13-04-1987) y su reglamento, siendo su órgano máximo la asamblea comunal. Las autoridades oficiales a las que se recurre frecuentemente son los Jueces de Paz, y luego el subprefecto o a la policía. En la medida en que las comunidades se van consolidando, dejan de recurrir a la justicia oficial y resuelven sus problemas con las autoridades comunales ${ }^{58}$. La Asamblea comunal insta por arreglos entre las partes, y recurre también a normas oficiales (ley de comunidades campesinas, Estatuto de comunidades campesinas), a fin de evitar colisiones con el derecho oficial.

\subsection{Bolivia}

A partir de la reforma de 1994 la Constitución Política reconoce que Bolivia, el país con mayor porcentaje de indígenas en América Latina, es una "sociedad pluricultural y multiétnica", y les reconoce también sus derechos colectivos ${ }^{59}$. Su art. 171 reconoce "los derechos económicos, sociales y culturales de los pueblos indígenas que habitan el territorio nacional [...] especialmente los relativos a sus tierras comunitarias de origen"

55 Así, Hurtado Pozo, J. ob. cit., pp. 380-381.

56 Del Castillo, L.: "Perú: entre la jurisdicción especial de las comunidades y la unidad del poder judicial”, en Giraudo, L. (Ed.), ob. cit., 208, pp. 243-264, pp. 254-255.

${ }^{57}$ Hurtado Pozo, J. ob. cit., p. 382.

58 A pesar de que en algunos lugares la justicia comunal se va debilitando debido a la parcelación individual de tierras comunales, la municipalización de las comunidades, entre otros. Hurtado pozo, ob. cit., p. 382.

${ }^{59}$ Molina, R. "La justicia comunitaria en Bolivia: cambios y continuidades”, en Giraudo, L. (Ed.), ob. cit., 2008, pp. 95-126; pp. 99 y ss. 
así como la posibilidad de sus autoridades para ejercer "funciones de administración y aplicación de normas propias como solución alternativa de conflictos, en conformidad a sus costumbres y procedimientos, siempre que no sean contrarias a esta Constitución y las leyes".

A pesar de este reconocimiento en el Código Penal boliviano no se encuentra ninguna norma específica que reconozca valor a la diversidad cultural como eximente de responsabilidad penal. Pero el Código Penal boliviano de 1972 sí contemplaba una causal de exculpación mediante la consideración del indígena como inimputable, la que fue derogada a finales de $\operatorname{los}$ años $70^{60}$, permaneciendo solo normas generales sobre inimputabilidad (arts. 17 y $18 \mathrm{CP}$ ) y error de tipo y de prohibición (art. 16 CP). En cambio, se consideró como atenuante de responsabilidad penal general "cuando el agente sea un indígena carente de instrucción y se pueda comprobar su ignorancia de la ley"(art. 40.4 CP). Nótese que la referencia a la "ignorancia de la ley" supone la consideración de una especie de error de prohibición directo incompleto (razón por la cual solo produciría efectos atenuatorios), lo que no se logra entender es por qué no hay exculpación si al carecer de instrucción e ignorar la ley por este mismo motivo, parece ser que se trata de un error de prohibición invencible, excluyente de la responsabilidad según el mismo art. 16 del CP boliviano.

El Anteproyecto de Código Penal boliviano ${ }^{61}$ realiza un reconocimiento expreso al pluralismo cultural y a la justicia comunitaria incorporando el error de prohibición o de comprensión culturalmente condicionado para aquellos casos en que la atipicidad de la conducta realizada conforme a la justicia comunitaria afecte Derechos Humanos o resulte gravemente discriminatoria estableciendo en cada caso su grado de vencibilidad. También para aquellos casos en los que el error culturalmente condicionado sea de tipo ${ }^{62}$. Así se reforma el art. 19 del CP, incorporando un inciso segundo que se refiere al error de tipo culturalmente condicionado ${ }^{63}$ considerando "que una cultura originaria puede tener una idea diferente de la causalidad... y lo que para nosotros sería una agresión o una lesión, para las personas que comparten esa visión puede ser un tratamiento curativo"64.

${ }^{60}$ Paul Amry, R. "Defensa cultural y pueblos indígenas: propuestas para la actualización del debate", en Derecho Penal y pluralidad cultural. Anuario de Derecho Penal 2006, pp. 73-100, p. 89.

${ }^{61}$ Parte General del Anteproyecto de Reforma al Código Penal de Bolivia. Conforme a la Resoluciones adoptadas en Santa Cruz de la Sierra (2008) y Buenos Aires 2008-2009). Disponible en http//cuestionpenal. blogspot.com

${ }^{62}$ Zaffaroni, E. R. "Consideraciones previas para la elaboración de un Código Penal para Bolivia”, en Parte General del Anteproyecto de Reforma al Código Penal de Bolivia. Según las Resoluciones adoptadas en Santa Cruz de la Sierra (2008) y Buenos Aires 2008-2009). Disponible en http//cuestionpenal.blogspot.com, p. 4.

63 Art. 19 inc. 2: "Tratándose de personas pertenecientes a culturas originarias, el tribunal tendrá especialmente en cuenta los condicionamientos culturales que impidan o dificulten el reconocimiento de los elementos constitutivos del tipo penal".

${ }^{64}$ Zaffaroni, E. R. "Consideraciones acerca del ...”, ob. cit., p. 25. 
En la misma disposición y a continuación del error de prohibición se contempla el error de comprensión culturalmente condicionado ${ }^{65}$.

En materia procesal penal, se respeta el principio de ne bis in idem para los actos conocidos y sancionados por la justicia comunitaria, siempre que no contravengan la Constitución y las leyes (arts. 28 y 53 inciso $5^{\circ}$ Código de Procedimiento Penal), y se contemplan reglas especiales para el juzgamiento de indígenas conforme a la legislación oficial: derecho a traductor o a que el juicio se sustancie en la lengua del lugar donde se celebra el juicio (arts. 11,113, 115 CPP), necesidad de contar con un perito especializado en asuntos indígenas (art. 391 CPP).

El Anteproyecto de Código penal boliviano se refiere al sistema comunitario diferenciándolo de otros sistemas oficiales que resuelven conflictos indígenas de relevancia penal tales como jueces de paz, y que se podrían aplicar entre indígenas urbanos ${ }^{66}$. Entre los principios rectores de este Código penal se establece que, "en caso de duda acerca de la competencia, esta se resolverá a favor del sistema que mejor resuelva el conflicto, respete el pluralismo cultural y conserve o restablezca la paz social" 67 , salvo en cuanto se trate de "hechos contra la vida, la integridad física o la libertad sexual cuya impunidad importe una grave lesión a la dignidad humana", en cuyo caso rige la justicia oficial. Se establecen ciertos límites a las sanciones indígenas en cuanto ellas no pueden ser inhumanas, crueles o degradantes, sin que puedan considerarse como tales aquellas que forman parte de un rito de reincorporación del individuo a su comunidad (art.12) y se prohíbe la doble punición de hechos juzgados por la justicia comunitaria (art. 13).

\subsection{Chile}

A diferencia de los anteriores, la Constitución Política chilena no reconoce a los pueblos indígenas, siendo uno de los países más atrasados de Latinoamérica en estas materias $^{68}$. La Ley $\mathrm{N}^{\circ} 19.253$ de 1993 , que establece Normas sobre protección, fomento y desarrollo de los indígenas y crea la Corporación Nacional de Desarrollo indígena, llamada Ley Indígena, reconoce la existencia de "etnias" (mas no de pueblos originarios) ${ }^{69}$.

${ }^{65}$ Art. 19 inciso 50: "También se excluye la culpabilidad cuando el agente por su cultura o costumbres no comprenda la criminalidad de su obrar o no se le pueda exigir que adecue su conducta a dicha comprensión. Cuando por las mismas causas no se excluya totalmente la posibilidad de comprensión o de adecuación de la conducta, el tribunal establecerá la pena conforme al grado de exigencia que podría formulársele"

${ }^{66}$ Una interesante descripción sobre el funcionamiento de la justicia comunitaria en Bolivia se encuentra en Cóndor, E. (Coord.), Rivera, E., Mendoza, M.A. Normas, procedimientos y sanciones de la justicia indígena en Perú. Comisión Andina de Juristas, Lima, 2010.

${ }^{67}$ Parte General del Anteproyecto de Código Penal para Bolivia, ob. cit., p. 22.

${ }^{68}$ En esta opinión Clavero, B. "Reconocimiento de Estados (no indígenas) por Pueblos (indígenas): Chile y Mapu, Caso y categoría”, en Giraudo, L. (Ed.), ob. cit., 2008, pp. 107-128, p. 126. También en la misma obra colectiva Giraudo, L. "Entre rupturas y retornos: la nueva cuestión indígena”, pp. 7-57, p. 13. También Emiliano Borja, catedrático de derecho penal, Universidad de Valencia, Valencia, España, entrevista de 24 enero 2012.

${ }^{69}$ El senador por la IX Región, Alberto Espina, afirmó en su día que: "quieren utilizar la palabra pueblo para los efectos de reconocer a las comunidades, ocurre que la Constitución chilena reserva la palabra pueblo para todos 
El Convenio 169 de la OIT comenzó a regir recién en 2009, aprobado tras 17 largos años de discusión en el Congreso, lo que motivó la presentación de un proyecto de reforma constitucional en 2010 que ha contado con el rechazo de la mayoría de los indígenas y organizaciones que les apoyan ${ }^{70}$, así también de la doctrina ${ }^{71}$. Como ha señalado el Instituto Nacional de Derechos Humanos en su informe de 2011, los esfuerzos que el Estado ha hecho en materia de políticas públicas: "han cedido ante el desconocimiento institucional del carácter multicultural del Estado que se erige como uno de los factores que entorpece el pleno ejercicio y goce de los derechos individuales y colectivos de que son titulares, contribuyendo a perpetuar la invisibilización de los pueblos y la mantención de relaciones con el Estado caracterizadas por el conflicto"72.

La ausencia de reconocimiento constitucional ha obligado a articular una interpretación de la Constitución que permita apoyar la búsqueda de soluciones en materia penal. En tal sentido, las disposiciones del Convenio 169 OIT deben ser interpretadas a la luz del art. 5 de la Constitución, norma que otorga un estatus especial a los tratados internacionales sobre derechos humanos, y que permite afirmar que en la medida en que estos se constituyen como un límite a la soberanía y se incorporan al derecho interno quedan derogadas todas las normas jurídicas que sean incompatibles con aquel ${ }^{73}$, tal y como lo ha reconocido la propia Corte Suprema ${ }^{74}$. Se forma así un bloque constitucional de derechos que limita el actuar de los poderes públicos y a la vez obliga a su promoción.

los chilenos, cualquiera sea su origen, e incluso señala que es ilegal e inconstitucional que cualquier grupo de personas se arrogue el uso de la palabra pueblo. La palabra pueblo ba ido otorgando a quienes la detentan la posibilidad de autodeterminación, esto significa separarse del Estado de chile, y así los grupos más radicalizados y violentistas lo dicen en todas sus proclamas". Entrevista documentada en Tótoro, D. "Üxüf Xipay - El Despojo”. Video Documental, Ceibo Producciones. Santiago de Chile, 2004.

${ }^{70}$ Se critica por ejemplo la ausencia de consulta a los pueblos indígenas, el no reconocimiento a los pueblos indígenas como sujetos de derechos (hace referencia a "personas indígenas" y "comunidades indígenas"), si bien reconoce derechos culturales, no reconoce los derechos de participación según las normas internacionales, y aún más, señala que los derechos culturales serán ejercidos "en la forma que establece el orden jurídico nacional”, con lo cual hace dependiente los derechos de los pueblos indígenas y sus propios ordenamientos sancionadores del derecho nacional, con lo cual las fuentes de derecho indígena no son las leyes internacionales, sino la legislación oficial. Asimismo suprime el régimen especial de protección existente sobre los derechos de aguas aymaras y atacameñas (indígenas del Norte), y somete las aguas indígenas al régimen jurídico general.

${ }^{71}$ Clavero, B. "Chile: reforma constitucional cancelatoria de derechos indígenas", disponible en http:// clavero.derechosindigenas.org (fecha consulta: 20-02-2012).

${ }^{72}$ Instituto Nacional de Derechos Humanos. Situación de los Derechos Humanos en Chile. Informe Anual 2011, Andros Impresores, Santiago, Chile, 2011, p. 35.

73 Silva Bascuñán, A. Tratado de Derecho Constitucional, Tomo IV. La Constitución de 1980, Bases de la institucionalidad. Nacionalidad y ciudadanía. Justicia Electoral, $2^{a}$ edición, Editorial Jurídica de Chile, Santiago de Chile, 1997, p. 121.

74 "Esta Corte Suprema, en reiteradas sentencias ha reconocido que de la historia fidedigna del establecimiento de la norma constitucional contenida en el artículo $5^{\circ}$ de la Carta Fundamental se deduce que los derechos esenciales limitan la soberanía y son "superiores a toda norma que puedan disponer las autoridades del Estado, incluido el propio poder constituyente, lo que impide que sean desconocidos: "superiores a toda norma que puedan disponer las autoridades del Estado, incluido el propio poder constituyente, lo que impide que sean desconocidos". Revista Fallos del Mes N ${ }^{\circ} 446$, Sección criminal, p. 2066, considerando $4^{\circ}$, citado en Nogueira, H. "Las constituciones y los tratados en materia de 
A la vez, las normas de derecho internacional acarrean como consecuencia una resignificación de las normas de derecho interno que se refieran o incidan sobre derechos humanos fundamentales ${ }^{75}$, siendo en este punto en el que nos encontramos con las normas penales.

A este respecto, en nuestro país se aprecia un monoculturalismo que se limita a reconocer la costumbre indígena en los siguientes términos: "La costumbre hecha valer en juicio entre indígenas pertenecientes a una misma etnia constituirá derecho, siempre que no sea incompatible con la Constitución Política de la República. En lo penal se la considerará cuando ello pudiere servir como antecedente para la aplicación de una eximente o atenuante de responsabilidad penal.

Cuando la costumbre deba ser acreditada en juicio podrá probarse por todos los medios que franquea la ley y especialmente por un informe pericial que deberá evacuar la corporación a requerimiento del tribunal” (art. 54 de la Ley $\mathrm{N}^{\circ} 19.253$ ).

Este reconocimiento a la costumbre indígena, como mero "antecedente" para la aplicación de una eximente o atenuante, "no es otra cosa que reducir el valor del 'derecho propio indígena' a las 'circunstancias personales' de quien cometió el hecho punible"76. A ello se suma la ausencia de valor jurídico para los sistemas sancionatorios que puedan pervivir en algunos de nuestros pueblos originarios y comunidades indígenas, como por ejemplo, en algunos pueblos aymaras que mantienen sistemas de resolución de conflictos, especialmente de índole familiar (incluida VIF), los que son conocidos y juzgados por las autoridades elegidas para impartir justicia, o por "los padrinos", o dirigentes, pero sus resoluciones no son vinculantes ni para el Estado ni para las partes mismas ${ }^{77}$.

\section{Algunas reflexiones para abrir el Debate en la LEGISLACIÓN PENAL SUSTANTIVA CHILENA}

La problemática indígena en Chile manifestada en una creciente criminalización de la demanda territorial ${ }^{78}$, unida a las obligaciones internacionales que el Estado de Chile

derechos humanos: América Latina y Chile", Rev. Ius et Praxis, año 6 N $^{\circ}$ 2, 2002,pp. 229-279, esp. p. 265. También en Sentencia Corte Suprema, Rol No 3452-2006, v/s contra Zapata y Romo, considerando $73^{\circ}$.

75 Meza-Lopehandía, M. "El Convenio No 169 OIT en el sistema normativo chileno”, en MezaLopehandía., M. (Ed.). Las implicancias de la ratificación del Convenio $\mathrm{N}^{0} 169$ de la OIT en el sistema normativo chileno, publicación de Observatorio ciudadano, 2011, pp. 66-96. Disponible en www.observatorio.cl. (fecha consulta: 07-08-2012). En contra de esta postura, el Tribunal Constitucional ha declarado, entre otros fallos, que: "aunque aparezca obvio, la norma constitucional reformada (en 1989) no consagró que los tratados internacionales sobre derechos esenciales tuvieran una jerarquía igual o superior a la Ley Fundamental" (Fallo rol 346, de abril de 2002, sobre el Tribunal penal Internacional).

${ }^{76}$ Carmona, C. ob. cit., p. 13.

77 Correa, P., Gundermann, K., et al. Mediación Intercultural. Estudio sobre conflictividad y modelos de intervención. Santiago de Chile: Ministerio de Justicia, Corporación Nacional Indígena, Universidad Diego Portales, 2009.

${ }^{78}$ Ampliamente Villegas, M. Derecho Penal del enemigo y la criminalización del pueblo mapuche. Ediciones La Cátedra, 2009. La misma, "El mapuche como enemigo en el derecho penal: Consideraciones desde la biopolítica y el derecho penal del enemigo", en Portal Iberoamericano de las Ciencias Penales, disponible en http//scribd.com. Cassigoli y M. Sobarzo (eds). Biopolíticas del Sur, I. Capítulo: "El otro como enemigo en el derecho 
ha contraído mediante la ratificación del Convenio 169 de la OIT, amén de las recomendaciones que ha hecho Naciones Unidas mediante los informes de sus relatores Rodolfo Stavenhagen y luego James Anaya, nos instan a intentar buscar soluciones, comenzando por las que puedan proponerse dentro de la legislación penal oficial. No pretende agotarse en este trabajo, pues aun quedan muchos temas por tocar, por ejemplo, los límites a los derechos de los indígenas, cuestión que determina en gran medida la naturaleza de las soluciones que puedan encontrarse. Quisiera simplemente dejar esbozadas algunas ideas.

El Convenio 169 contiene un mandato general de respeto a la costumbre indígena y su derecho consuetudinario ${ }^{79}$ que se concreta en el ámbito penal especialmente en el art. 9.2 que establece que las autoridades y los tribunales llamados a pronunciarse sobre cuestiones penales deberán tener en cuenta las costumbres de dichos pueblos en la materia. Este artículo, que forma parte del bloque de constitucionalidad, ordena tomar en cuenta la costumbre indígena para definir la responsabilidad penal ${ }^{80}$. Tal y como vimos al examinar la legislación comparada, las soluciones más aceptadas para los delitos culturalmente motivados ${ }^{81}$ son aquellas que fijan una causal de exculpación para el indígena que infringe normas de derecho oficial. Esto no obsta a encontrar posibles causas de justificación y atipicidad, así como de atenuación de la responsabilidad penal (caso Bolivia) ${ }^{82}$.

\section{La exculpación}

Dejando intacto el injusto penal, se sitúa el fundamento de la irresponsabilidad penal en el ámbito de la culpabilidad, mediante la inimputabilidad, de la consideración de un error de prohibición o de un error de comprensión culturalmente condicionado, o de la presencia de una fuerza irresistible.

(penal).Especial referencia al conflicto mapuche”, Editorial Universidad Arcis, 2010. Villegas, M., Quintana, L., Meza-Lopehandía, M., Díaz, F., Jaque, I., Saavedra, S. El ejercicio de derechos como acto subversivo y la respuesta estatal: El Derecho Penal del Enemigo. Iniciativa interdisciplinaria en Conflicto Mapuche y Derecho Penal. Programa de investigación Domeyko. Subprograma sujetos y actores sociales. Universidad de Chile. Marzo 2010. Portal Iberoamericano de las Ciencias Penales, Disponible en http//scribd.com.

79 Art. 8 Convenio 169: 1. “Al aplicar la legislación nacional a los pueblos interesados deberán tomarse debidamente en consideración sus costumbres o su derecho consuetudinario. 2. Dichos pueblos deberán tener el derecho de conservar sus costumbres e instituciones propias, siempre que estas no sean incompatibles con los derechos fundamentales definidos por el sistema jurídico nacional ni con los derechos humanos internacionalmente reconocidos. Siempre que sea necesario, deberán establecerse procedimientos para solucionar los conflictos que puedan surgir en la aplicación de este principio”.

${ }^{80}$ Otra norma importante pero que no trataremos en esta oportunidad es el Art. 10 que establece un deber de especial consideración a las características económicas, sociales y culturales de los pueblos indígenas a la hora de imponer sanciones penales previstas por la legislación general a sus miembros, especificando que deberá darse la preferencia a tipos de sanción distintos del encarcelamiento.

${ }^{81}$ Los delitos culturalmente motivados se definen como aquellas conductas que si bien contradicen una norma penal, se explican en razón a la cultura a la que pertenece el infractor, supuesto que este pertenece a una cultura minoritaria, dentro de la cual esa conducta es atípica, o está justificada o exculpada, o siendo delito, es tratada de manera distinta. Carnevalli, R. Ob. cit., pp. 24-25.

${ }^{82}$ Coincido en este punto, aunque no en su construcción dogmática, con Modolell, J.L., ob. cit., pp. 273-286. 


\subsection{La inimputabilidad del indígena}

En cuanto a la consideración del indígena como inimputable, solución adoptada por el Código Penal colombiano, coincido con quienes estiman que lleva inserta una subvaloración del indígena al asimilarlo al inimputable por trastorno mental, debido a que su inimputabilidad vendría dada por inmadurez psicológica ${ }^{83}$. Si bien algunos tratan de hacer la diferencia y lo asocian a una inmadurez cultural ${ }^{84}$, me parece que no logra hacerse cargo de la idea central, esto es, que el indígena es inimputable porque es un "anormal" que no ha logrado adaptarse a la cultura dominante. Coincido con Sotomayor cuando indica que más allá de las buenas intenciones de estos planteamientos sobre la inmadurez cultural, de todas formas parten asumiendo como válidos o verdaderos únicamente a aquellos valores sobre los que se asienta el sistema penal, valores estos que a su vez son asumidos como generales $y$, finalmente, convertidos en lo absoluto y la asunción de los mismos en lo racional; de donde lo que no se ajusta a estos moldes y parámetros es luego individual o colectivamente patologizado o descalificado ${ }^{85}$.

\subsection{El error de prohibición}

El error de prohibición, esto es, aquel que impide la comprensión de la antijuridicidad por inexistencia de esa conciencia de la ilicitud que ha de ser exigible al sujeto para atribuirle responsabilidad ${ }^{86}$ es acogido en legislaciones como la peruana y la boliviana. La exigibilidad de la conciencia del injusto implica un proceso de internalización de un determinado valor del sistema (el que la norma quiere proteger), que si no se ha dado, impide al Estado exigir responsabilidad penal ${ }^{87}$. El error de prohibición asume diversas formas, lo que determina la inexigibilidad es "la no comprensión de estar prohibido el acto mismo"88. El error directo de probibición es "el que recae sobre la norma misma", mientras que el error indirecto de prohibición es aquel que consiste en "la falsa convicción de que opera en el caso una causa de justificación" ${ }^{89}$.

El problema asociado al error de prohibición es precisamente que el acto sigue siendo antijurídico, de manera tal que se vuelve a la idea de imposición de unos valores (los de la cultura dominante) sobre otros. Coincido con Modolell en este punto, mas no en la idea de distinguir según el grado de "integración” del indígena para determinar si

${ }^{83}$ Becerra, C. Ob. cit., pp. 219-220. También en Sotomayor Acosta, J. O. "La responsabilidad penal del indígena en Colombia. Entre el mundo real y un mundo posible”. Jueces para la democracia, N ${ }^{\circ} 26,1996$, pp. 89-96.

${ }^{84}$ Sobre esta discusión véase las críticas que se hacen a las posturas De Reyes Echandía y Mireya Bolaños en Modolell, J.L. Ob. cit., pp. 275 y 276.

85 Sotomayor, J. Ob. cit., p. 91.

${ }^{86}$ Zaffaroni, E.R., Alagia, A., Slokar, A. Derecho Penal. Parte General. Edit. Ediar, Buenos Aires, $2^{\mathrm{a}}$ edición, 2002, p. 733.

${ }^{87}$ Bustos, J., Hormazábal, H. Lecciones de Derecho Penal. Edit. Trotta, Barcelona, 1997, p. 347.

${ }^{88}$ Zaffaroni, E.R., Alagia, A., Slokar, A., ob. cit., p. 734.

${ }^{89}$ Ídem. 
la exclusión de su responsabilidad penal se da en el ámbito de la culpabilidad, el de la antijuridicidad o de la tipicidad ${ }^{90}$. Me parece que con ello sigue partiéndose de la base de una cultura dominante que impone valores al otro distinto. Un indígena puede estar perfectamente integrado y actuar porque obedece a una conciencia de ilicitud distinta, que no dice relación con la "comprensión" de la norma, sino con un rechazo de la norma oficial porque obedece a una norma propia o porque la norma oficial se contradice con la norma propia (ej. caso de usurpaciones de terrenos ancestrales). La situación que se plantea es muy similar a la de los delincuentes por convicción, que obedecen en su actuar a una especie de "supra derecho". Por eso, no comparto que "el indígena integrado debe ser tratado igual que el resto de los destinatarios de las normas" 91 , me inclino más por pensar que el indígena, integrado o no, o bien actúa bajo ejercicio legítimo de un derecho o a lo sumo bajo un error culturalmente condicionado (de tipo o prohibición).

Muy excepcionalmente, en Chile, se admitió el error de prohibición en un delito cometido por mapuches con motivo de demanda territorial. Es el caso de Isla Butacheuques ocupada por huilliches. Se acusó a la autoridad ancestral huilliche por los delitos de usurpación y hurto de madera por haber ocupado territorio fiscal de un aserradero ubicado en la isla y haber usado la madera. El acusado alegó que ese territorio pertenecía a sus ancestros, lo que probó mediante testigos y demanda territorial interpuesta ante el organismo competente. El Tribunal de Garantía lo absolvió por considerar que actuó en error de prohibición, resolución que confirmó la Corte de Apelaciones de Puerto Montt rechazando el recurso de nulidad interpuesto por el Ministerio Público, puesto que el imputado jamás pudo representarse la ilicitud de su conducta [...] su familia ya se encontraba en ese lugar en donde se encuentra el aserradero, que sus antepasados ocuparon esas tierras mucho antes de 1912 cuando el Estado de Chile inscribió esas tierras como suyas, manifiesta que él toda su vida ha trabajado con madera aserrada, que el camino que da hacia el aserradero tiene al menos 150 años, pues su abuelo fue quien lo ayudó a construir [...] El contexto en que ocurren los hechos es en una comunidad aislada en que la única posesión inscrita es la del Estado de Chile... Si bien el imputado inició el trámite de regularización de su ocupación, esto respondía a un criterio que se estaba adoptando en la Isla Butacheuques por parte de todos sus ocupantes, con el fin de regularizar una situación de hecho ${ }^{92}$.

Pienso que en este caso el imputado no actuó "erradamente" sino en ejercicio legítimo de su derecho al territorio. Probó que la tierra era ancestral y que perteneció a sus abuelos. Que el Estado de Chile haya desconocido unilateralmente Pactos como el de Tapihue $(1825)^{93}$ y el de Quilín (1641) ${ }^{94}$, así como los títulos de merced otorgados, procediendo a colonizar territorios que pertenecían a los indígenas, no incide en la legitimidad del

\footnotetext{
${ }^{90}$ Modolell, J.L. Ob. cit., p. 280 y ss.

${ }^{91}$ Modolell, J.L., p. 285.

92 Considerando Quinto Sentencia Corte de Apelación de Puerto Montt 13/06/2008, Rol 92-2008.

93 Correa, M., Molina, R., Yáñez, N. La reforma agraria y las tierras mapuches. Chile 1962-1975, Edit.
} LOM, Santiago de Chile. 2005.

${ }^{94}$ Bengoa, J. El Tratado de Quilin: documentos adicionales a la historia de los antiguos mapuches del sur, Ed. Catalonia, Stgo. Chile, 2007. 
ejercicio de su derecho a recuperar el territorio. Como hemos sostenido en otro lugar, nos parece que la antijuridicidad no se satisface, ni en su aspecto formal ni en su aspecto material. No es antijurídico formalmente, pues de acuerdo con la normativa internacional sobre derechos de pueblos indígenas que viene a limitar la soberanía del Estado de Chile de conformidad con el art. 5 inciso 2 de la Constitución Política, no se trata de un acto contrario al ordenamiento jurídico. No es antijurídico materialmente, pues no hay lesión a bien jurídico alguno, ya que ese bien jurídico pertenece a los comuneros ${ }^{95}$.

\subsection{El error de comprensión culturalmente condicionado}

Solución defendida, entre otros, por Zaffaroni, esta clase de error excluye la culpabilidad cuando el sujeto por su cultura o sus costumbres no comprende la ilicitud o no se le pueda exigir que adecue su conducta a esta comprensión. En otros casos no excluye la culpabilidad pudiendo solo atenuarla. No se trata de un desconocimiento de la prohibición (ni total ni parcial), sino de la ausencia de internalización de la misma por parte del sujeto, por su pertenencia a una cultura distinta. La comprensión se exige cuando la persona tiene una posibilidad efectiva de incorporar el valor que la norma protege a su acervo psicológico, existiendo casos en los que la persona "conoce el desvalor, pero no puede proceder a su introyección" 96 , pues experimenta otra conciencia, una conciencia disidente ${ }^{97}$. Esta conciencia disidente tiene mucha relevancia cuando el autor está convencido que obra amparado por una causa de justificación que le dispensa del cumplimiento de una norma, por ejemplo, haciendo uso del ejercicio legítimo de un derecho. En este caso se encuentra en un error indirecto de prohibición.

Los efectos exculpantes de este error dicen relación con que "el sujeto haya tenido la posibilidad de internalizar los valores del sistema en un grado razonablemente exigible" 98 , caso este último en el que el injusto será reprochable, quedando afectado el grado de reprochabilidad según el grado de exigibilidad, pues "el sujeto que experimenta como un deber de conciencia la necesidad de cometer el injusto debe realizar un esfuerzo mucho mayor para evitarlo que el correspondiente a quien comete el injusto sin experimentar esta vivencia"99. Por tanto, la conciencia disidente tendría que ser al menos una causa de disminución de la culpabilidad (atenuante).

Existen también casos en los que esta conciencia disidente permite la exculpación y esto ocurre cuando el esfuerzo que ha debido realizar el autor sea tan grande que no

95 Villegas, M., Quintana, L., Meza-Lopehandía, M. et al. Ob. cit., p. 270. Si bien al momento de los hechos no se encontraba vigente el Convenio 169, conviene tener presente las consecuencias que este trae para la garantía constitucional de propiedad del art $19 \mathrm{~N}^{\circ} 24$. Un buen análisis sobre el punto en Meza-Lopehandía, M. “Territorio y Autonomía de los Pueblos Originarios en Chile. Una mirada desde el ordenamiento jurídico chileno y la urgencia del Reconocimiento". Memoria para optar al grado de Licenciado en Ciencias Jurídicas y Sociales, Facultad de Derecho, Universidad de Chile, 2009.

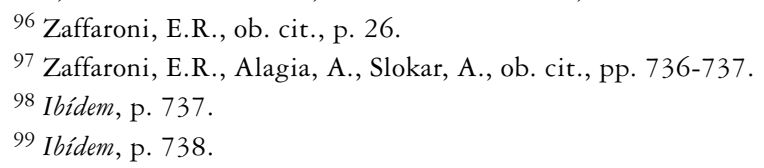


pueda exigírsele jurídicamente y por tanto quede excluida la reprochabilidad (un error invencible condicionado culturalmente). Este supuesto se da cuando el sujeto conoce la norma pero no es posible que la internalice por razones culturales. Ahora, no todo error culturalmente condicionado es error de prohibición directo, pues el condicionamiento cultural también puede dar lugar a errores de tipo. En todo caso, cuando el error de comprensión y el error culturalmente condicionado se superponen, elimina la culpabilidad.

Luego, según sea vencible o invencible los efectos de este error serán atenuar la responsabilidad o excluirla completamente. La discusión surge en este último caso cuando se afectan bienes jurídicos de mayor importancia (vida, integridad física).

\subsection{La fuerza irresistible}

Por último, una de las vías que se usó en los tribunales chilenos, antaño, fue la de considerar que cuando el indígena actúa según su cultura, lo hace exculpadamente pues obedece a una fuerza irresistible, una especie de vis compulsiva cultural. Ello sucedió en el trágico caso del terremoto de 1960, en Puerto Saavedra (IX Región) en donde fueron absueltos unos mapuches que sacrificaron un niño para calmar la furia del mar ${ }^{100}$. Así también en 1953, en Valdivia, la justicia absolvió, por obrar bajo fuerza irresistible, a una mujer mapuche (Juana Catrilaf) que mató a su abuela, bruja conocida por su entorno, pues le atribuyó ser la causa directa de sus desgracias, y tenía temor a sufrir graves males, incluyendo perder la vida ${ }^{101}$.

Modernamente tiende a rechazarse la exculpación por esta causal como sucedió en el ajusticiamiento con resultado de muerte que hicieron unos jóvenes indígenas de la localidad de Rucatraro (IX Región) al homicida del padre biológico de uno de los acusados, el que según la comunidad, no había sido suficientemente castigado por la justicia chilena y además se presentaba continuamente en la comunidad a molestar. La defensa alegó que los hechos debían apreciarse en el marco de la cultura en la cual ocurrieron según la cual si se presenta un factor o elemento que altera la vida comunitaria se debe intentar neutralizarlo, si no resulta aislarlo, y si esto no resulta, debe eliminárselo. De esta forma el hijo de la víctima (B.H.) estaba "obligado", o "irresistiblemente impulsado" (art. $10 \mathrm{~N}^{\circ} 9 \mathrm{CP}$ ) a eliminar físicamente al hechor.

El tribunal rechazó la defensa y condenó a los acusados porque no se había probado fechacientemente la existencia en la comunidad de Rucatraro, la costumbre ancestral de aplicar pena de muerte a un homicida si la justicia chilena no lo hace pagar su deuda

${ }^{100}$ Sentencia de 2 de octubre de 1962, causa Rol N ${ }^{\circ} 24.228$, dictada por doña Ester Valencia Durán. Citado por Lillo, R. "El convenio 169 de la OIT y la defensa penal de indígenas". Minuta regional No 1/2010/ abril. Defensorías Regionales. Defensoría Penal Pública. Chile, 2010, p. 6.

${ }^{101}$ Sentencia de 4 julio de 1953, dictada por doña María Mardones Montenegro, Jueza Subrogante del Segundo Juzgado de Letras de Valdivia. Confirmada por la Corte de Apelaciones de Valdivia en sentencia de 7 de diciembre de 1953. Revista de Derecho y Jurisprudencia y Gaceta de los Tribunales, año 1955, T. LII, segunda parte, secc. $4^{\mathrm{a}}$, pp. 85 y ss., $\mathrm{N}^{\circ} 5$ y 6 ). 
con la sociedad ${ }^{102}$. Además: Es cierto que el enjuiciado dijo que a J.C. lo mataron a golpes de puñal porque siempre "los estaba molestando", causando "mal", pero tal aseveración y teniendo presente que también admitió haber estado bajo los efectos del alcobol cuando actuó, no permite cobijar en ella un sentimiento de "venganza motivada por mandato de costumbres ancestrales", $e$ ignorancia de la ley, para aceptar transformarse en brazo ejecutor de la justicia de sus antepasados; a este último respecto cabe tener presente que H.P. se declaró católico ante su entrevistador y que de ningún sincretismo entre la Cosmovisión mapuche y el Cristianismo puede resultar la aceptación de la pena de muerte aplicada en circunstancias como la del caso sub lite $e^{103}$.

\section{La justificación}

Otra vía, defendida para algunos casos por parte de la doctrina ${ }^{104}$, es la exclusión de la antijuridicidad vía causal de justificación del ejercicio legítimo de un derecho o el cumplimiento de un deber. En nuestro país, el ejercicio legítimo de un derecho (art. 10 $\mathrm{N}^{\circ} 9 \mathrm{CP}$ ) encuentra asidero para algunas conductas llevadas a cabo por indígenas si se la relaciona con la normativa internacional (Convenio 169 y Declaración de ONU sobre derechos de los pueblos indígenas) incorporada como límite a la soberanía por el art. 5 inciso 2 de la Constitución Política. Así por ejemplo, en el caso de dos ciudadanas bolivianas de origen aymara que fueron sorprendidas por la policía chilena, portando entre sus pertenencias 10 bolsas de hojas de coca (aprox. 5 kilos 440 gramos) ${ }^{105}$. Declararon que era un encargo de una ciudadana chilena para pagar una manda a la Virgen de Andacollo. Fueron acusadas por tráfico ilícito de estupefacientes. El tribunal las absolvió, a mi entender, porque consideró, sin señalarlo, que existía un error de prohibición indirecto, pues en la conciencia de las acusadas su conducta no resultaba atentatoria a derecho, ya que es habitual que en su etnia sea corriente que en ese tipo de festividades se consuma y use las hojas de coca, lo que tiene gran importancia para el pueblo aymara tanto para su desarrollo cultural como para su idiosincrasia, máxime cuando aquello le es reconocido legalmente, mediante las normas señaladas. En consecuencia, las acusadas actuaron creyendo equivocadamente que se encontraban amparadas en la causal de justificación del artículo $10 \mathrm{~N}^{\circ} 10$ del Código Penal,

102 Conforme a la normativa nacional, la costumbre indígena puede probarse por cualquier medio. Las exigencias que los tribunales suelen pedir para los peritajes son: a) que se haga mención de fuentes bibliográficas o etnográficas (S. TOP Temuco 31 mayo 2006, RIT No 49-2006; S. CA de Temuco de 25-022009, Rol 567-2007) y b) que la conducta del imputado se atribuya a la costumbre ancestral que se invoca. Cuando solo se realiza un peritaje general sobre el pueblo originario y no se hace esta relación directa, los tribunales tienden a rechazar (SCA de Punta Arenas, 14-12-2002, Rol 914-2002, SCA de Concepción, de 18-02-2003, Rol 1344-2003, SCA Temuco, de 25-02-2009, Rol 567-2007). Castro, M., Vergara, J. (Eds.), Villegas, M., Albornoz, P. et al., Jurisprudencia Indígena. Cosmovisión y legislación, Programa de Antropología Jurídica Universidad de Chile. Ministerio de Justicia. Dic. 2009, p. 75.

103 Considerando $7^{\circ}$, Sentencia TOP Temuco, 31/05/2006, RIT 49-2006.

104 Así Modolell, ob. cit., pp. 281 y 282, quien la establece para el caso del indígena "no integrado" que realiza una conducta bajo el amparo de costumbres ancestrales.

${ }^{105}$ Un amplio análisis de este fallo en Barrientos, I. "Licitud del porte y uso de la hoja de coca". Rev. Política Criminal, No 5, 2008, pp. 1-30. Disponible en www.politicacriminal.cl (fecha consulta, 11-09-2011). 
por el ejercicio legítimo de un derecho, lo que obsta a la existencia de la conciencia de la ilicitud de su conducta ${ }^{106}$.

Cierto es que el fallo es ambiguo, pues en una de sus partes excluye el error, y más bien parece prohijar la idea de que las acusadas actuaron en ejercicio legítimo de un derecho $^{107}$, entregando toda una fundamentación al respecto, sin embargo la sentencia en el párrafo transcrito me parece hace clara referencia a un error de prohibición indirecto.

Este fallo fue confirmado por la Corte de Apelaciones al rechazar el recurso de nulidad interpuesto por el Ministerio Público, haciendo hincapié en la autoejecutividad de la normativa internacional de derechos humanos, en especial el Pacto Internacional de Derechos Civiles y Políticos en su declaración de igualdad para todos los hombres, lo que a juicio de la corte se traduce en el respeto a las minorías culturales y al principio de supremacía de la realidad, el que vendría a demostrar que en la comunidad residente en Calama y en todo su entorno altiplánico contiguo a Bolivia, prima el respeto y cultivo de tradiciones propias e intransferibles de su propia cultura [...]. El art.27 (PIDCP), a juicio de la Corte contiene la obligación del respectivo Estado de permitir a las personas pertenecientes a dichos, grupos manifestar sus diferencias de cultura e idioma. Ello es un derecho bumano digno de total respeto y observancia en cualquier comunidad jurídicamente establecida ${ }^{108}$.

Pienso que precisamente por los argumentos que se contienen en el fallo tanto del TOP como de la Corte, en efecto, estamos ante el ejercicio legítimo del derecho a desarrollar su cultura y su religión (art. $10 \mathrm{~N}^{\mathrm{o}} 10$ ) y no de un error, pues las mujeres actuaron conscientes de la licitud de su acto según su cultura ${ }^{109}$.

\section{La atipicidad}

En algunos casos, p.ej. tratamientos curativos con resultados de lesiones, podría argumentarse la atipicidad de la conducta debido a la presencia de un error de tipo culturalmente condicionado. Este error dice relación con la dificultad o impedimento que tiene el sujeto para reconocer los elementos constitutivos del tipo penal, en razón de sus condicionamientos culturales. Es un problema de conocimiento (y no de comprensión). Un caso en que se alegó en Chile fue el de un sujeto perteneciente a una comunidad pehuenche, de aproximadamente 40 años, que sostuvo relaciones sexuales con una menor de 13 años de edad, también de la misma comunidad, con consentimiento de la menor y en el domicilio de este, al cual acudió la menor. La madre de la menor, evangélica, denunció los hechos a la justicia. Fue acusado de cometer violación calificada (art.362 del CP).La defensa alegó que el sujeto había actuado en error de prohibición y también bajo un error de tipo. La existencia de error de prohibición la fundamentó en que ambos vivían en una comunidad relativamente aislada, y que en dicha comunidad era habitual

106 Considerando decimooctavo) STOP de Calama de 06/10/2007, RIT 66-2007, contra Idelza Huagama y otra.

${ }^{107}$ En esta interpretación del fallo, Barrientos, I., ob. cit., pp. 5 y 7. También Lillo, R., ob. cit., p. 19.

${ }^{108}$ Considerando Octavo. Sentencia Corte de Apelaciones de Antofagasta de 05/11/2007, Rol 250-2007.

${ }^{109}$ En esta opinión que comparto, Barrientos, I., ob. cit., Lillo, R., ob. cit. 
que a la llegada de la menarquía de las niñas, estas estuvieren en condiciones de poder relacionarse sexualmente con los hombres de la comunidad. El error de tipo lo fundamentó en que el sujeto desconocía la reforma penal que aumentó la edad de la víctima para considerar la existencia de una violación calificada.

El Tribunal rechazó esta tesis acudiendo a la idea del indígena "integrado": como ba quedado demostrado el imputado vive en una comunidad Pebuenche, a no más de 2 o 3 kilómetros de la localidad de Lonquimay, tiene en su hogar aparatos de televisión y radio, que lo conectan al resto del país y al mundo, mantiene contacto con organismos de la Comuna donde habita, además en su comunidad está fuertemente presente la Iglesia Pentecostal y él se reconoce como católico, ambas religiones son cristianas, doctrina que mantiene como elementos esenciales la probibición de las relaciones sexuales prematrimoniales y un ensalzamiento de la virginidad de la mujer, bajo sanciones de indole religiosos (pecado). A su vez, la madre de la menor manifestó que dentro de su comunidad la mujer se acostumbra a casar alrededor de los 20 años, y que primero lo hacen en el Registro Civil y después por la Iglesia [...] respecto a que en la idiosincrasia pebuenche o mapuche en general, la llegada de la menarquía o menstruación en la mujer, la hace disponible sexualmente para los varones adultos de la comunidad [... ] ello en caso alguno ha sido acreditado ... ${ }^{110}$.

La tesis sostenida por el tribunal entonces es que el indígena que se encuentra conectado con el mundo, y penetrado ideológicamente por la religión ya está integrado, y por ende no es posible admitir que desconozca la norma porque en este sentido ha de tratársele igual que a los no indígenas. El problema es que aquí no se trata de un simple desconocimiento de la norma, sino un desconocimiento que va apoyado por el hecho de pertenecer a una cultura en la que es lícito mantener relaciones sexuales consentidas con una menor de 13 años. Es decir, el esfuerzo que ha de hacer el sujeto para internalizar una norma como esta, conociéndola, es mucho mayor que el que debe hacer el no indígena. Pienso que en este caso nos encontramos ante un error de tipo culturalmente condicionado.

De todas formas, distinto habría sido que el Tribunal fundamentara su fallo en una eventual colisión entre los derechos de los indígenas garantizados por el convenio 160 de la OIT, y la Convención de Belem do Pará, que sanciona la violencia contra la mujer, caso en el cual me parece que nos encontramos ante una difícil situación, en la que, en opinión de expertos académicos, debía primar la Convención de Belem do Pará, pues se trata de derechos humanos ${ }^{111}$, y en opinión de expertos indigenistas, debe primar el respeto a la cultura indígena, sin perjuicio de los acercamientos interculturales que se puedan hacer entre la cultura dominante y las indígenas ${ }^{112}$.

${ }^{110}$ Considerando undécimo. STOP Temuco 23/11/2005, RIT 101-2005.

111 En esta opinión, Emiliano Borja Jiménez, catedrático de derecho penal, Universidad de Valencia: No hay colisión porque el Convenio 169 establece los propios límites... la justicia indígena y la costumbre indígena no pueden estar por encima de los derechos bumanos consagrados en una norma internacional que el propio país ha ratificado... si usted me pregunta si toda costumbre indígena debe ser respetada, No. Entrevista realizada en Valencia, España, 24 enero 2012.

112 En esta opinión, C.L., Defensor Indígena guatemalteco asesor y consultor de comunidades mayas: Lo que debe hacer el Estado es acercarse, establecer mecanismos de buena fe, consultas de buena fe para tratar de revertir cuestiones interculturales, porque a mí me parece apropiado que si hay otra cultura con la que se está conviviendo de alguna manera y ve que un acto la ofende, debe acercarse, creo que puede hacerlo, pero no creo que eso le faculte para imponerle a los demás, porque eso es colonialismo. Entrevista realizada en Ciudad de Guatemala, 13 abril 2011. 


\section{COnClusiones}

1. El pluralismo jurídico es expresión de la idea de democracia en cuanto implica no solo el respeto a las minorías, en este caso, culturales, sino también la posibilidad de que las mismas transiten hacia una legalidad alternativa propia, especialmente en el área penal. La relevancia penal del reconocimiento constitucional a los pueblos indígenas dice relación no solo con la posibilidad de que esta legalidad alternativa pueda ser posible, en el sentido de que sus costumbres puedan ser consideradas fuente de derecho penal, sino también en la medida en que puedan reconocerse jurisdicciones paralelas a la oficial y que deban coordinarse entre sí para funcionar.

2. Llama la atención que siendo México, Guatemala y Bolivia países con altísima población indígena y que han dado lugar incluso a movimientos guerrilleros indigenistas, sean tan pobres en cuanto al reconocimiento penal indígena. La presencia de jurisdicciones indígenas especiales (México, Ecuador) o de Juzgados de Paz o similares (Guatemala, Bolivia) solo resuelven el problema en parte, pues cuando son juzgados por la legislación oficial se les juzga igual que a un no indígena desde la perspectiva de las posibilidades de exclusión de responsabilidad penal. Bolivia por ejemplo, se conforma con reconocer una atenuante, la mayoría de los CP estatales en México consideran la calidad de indígena solo al momento de determinar y aplicar la pena y/o medida de seguridad, es decir, cuando el injusto permanece intacto, y la culpabilidad también. En Guatemala la situación es aún más grave, puesto que las concreciones legales de los acuerdos de Paz y de Identidad no han traído las reformas adecuadas en materia penal, contentándose con reconocer la forma de resolución de conflicto mediante alcaldías indígenas o cofradías, y los juzgados de paz en un sistema que ha sido mal valorado por expertos indigenistas, puesto que no constituye una consagración del pluralismo cultural, más bien reafirma la identidad monocultural del sistema jurídico guatemalteco. En Bolivia, siendo el país con mayor presencia indígena, hay un atraso inexcusable entre el reconocimiento que la Constitución hace de la multiculturalidad y las reformas a la legislación penal. Chile sigue siendo uno de los países que mayores atrasos presenta en adecuar su legislación a las obligaciones internacionales que ha contraído. La norma contenida en la Ley $\mathrm{N}^{\circ} 19.253$ es insuficiente.

3. De todas las soluciones que, dentro del derecho oficial, ofrece la legislación comparada, incluyendo aquella en discusión, ofrecen para hacerse cargo de la responsabilidad penal del indígena, me parecen inaceptables hoy la consideración del indígena como un inimputable y la de haber actuado por una fuerza irresistible o miedo insuperable. Me parece que la similitud entre ambas consiste en considerar al indígena infractor como un ser anormal, o que al menos su conducta ha sido "anormal". Son distintos, no anormales. En cambio, me parece que en muchos de los casos el indígena puede actuar justificado en razón del ejercicio legítimo de un derecho. En otros casos, consciente de que se trata de una solución que se ofrece desde los valores de la cultura dominante, actúa exculpado por haber incurrido 
en un error de comprensión o de tipo culturalmente condicionado. Me parece de suma importancia realizar un ejercicio de distinción entre las distintas clases de error, puesto que a veces no queda claro el fundamento de la exención de responsabilidad o de la atenuación que se reclama, y por eso ha de hacerse especial hincapié en qué tipo de conducta se trata, a saber: a) si se debe a un desconocimiento total o parcial de la norma penal o de sus reformas, o b) que el sujeto no comprende lo injusto de su actuar, no por desconocimiento de la norma, sino porque está obedeciendo a otra conciencia que lo determina en su actuar, o c) que el sujeto cree estar amparado por una causal de justificación que en realidad no lo ampara, o d) que el sujeto desconoce o no comprende alguno de los elementos del tipo penal.

4. La postura que aquí se adopta y que se manifiesta desde el momento en que las soluciones se buscan dentro del derecho penal oficial (según sea el caso, justificación vía ejercicio legítimo de un derecho o exculpación vía error de comprensión culturalmente condicionado), tiene un fundamento político criminal de viabilidad. Se ha querido aportar a un debate que recién se inicia en nuestro país ofreciendo una serie de posibilidades que se encuadran en un sistema normativo que todavía ni siquiera reconoce constitucionalmente a nuestros pueblos originarios, con plena conciencia de que hay temas fundamentales que no pudieron tratarse debido a la complejidad que suponen como son los límites al reconocimiento de la costumbre y el derecho consuetudinarios indígenas, así como las relaciones entre género e interculturalidad.

5. Idealmente la mejor solución es el reconocimiento a los derechos de los pueblos indígenas en un diálogo intercultural, que permita la existencia de órdenes jurídicos paralelos al oficial en el que las costumbres y tradiciones indígenas puedan servir como fuente de un derecho penal propio, órdenes jurídicos paralelos al oficial que supongan la devolución del conflicto a las comunidades indígenas para que estas ejerzan jurisdicción sobre sus miembros. Pero ello, en Chile, requiere de un ejercicio previo del poder legislativo en orden a sancionar (en el sentido de aprobar) constitucionalmente los derechos de los pueblos originarios. Mientras esto no suceda, nos veremos obligados a realizar interpretaciones normativas que no siempre son unívocas.

\section{BIBLIOGRAFÍA}

Aldunate, E., "Interpretación constitucional y decisión política”, en Revista de Derecho, Universidad Católica de Valparaíso, No XV, 1993-1994, pp. 31-65.

Aragón, O., "Los sistemas jurídicos indígenas frente al derecho estatal en México. Una defensa del pluralismo jurídico". Boletín Mexicano de Derecho Comparado, Nueva serie, XL (118), 2007, pp. 9-26.

BAQUIAX, J., "Error de prohibición culturalmente condicionado como causa de inculpabilidad". Tesis de Máster en Derecho Penal. Universidad de Sevilla. España, 2009, sin publicar.

Barrientos, I., "Licitud del porte y uso de la hoja de coca". Rev. Política Criminal, No 5, 2008, pp. 1-30. Disponible en www.politicacriminal.cl 
Becerra, C., "La jurisdicción especial indígena y el derecho penal en Colombia: Entre el pluralismo jurídico y la autonomía relativa". El Otro Derecho, No 35, 2006, pp. 213-236.

BengoA, J., El Tratado de Quilin: documentos adicionales a la historia de los antiguos mapuches del sur, Ed. Catalonia, Stgo. Chile, 2007.

BorJa, E., "Derecho indígena sancionador y derechos humanos", en Giraudo, L. (Ed.), Derechos, costumbres y jurisdicciones indígenas en la América Latina contemporánea, Cuadernos y Debates $\mathrm{N}^{\circ}$ 191, Centro de Estudios Políticos y Constitucionales, Madrid, 2008, 185-213.

Borja, E., "Sobre los ordenamientos sancionadores originarios de Latinoamérica". En Derecho penal y pluralidad cultural. Anuario de Derecho Penal, 2006, pp. 101-151.

BorJA, E., Introducción a los fundamentos del Derecho Penal Indígena, Edit. Tirant Lo Blanch, Monografías, Valencia, 2001.

Bou Franch, V., "En busca de un estatuto jurídico para los pueblos indígenas”, en Borja, E. (coord.) Diversidad cultural: conflicto y derecho, Tirant Monografías 419, Valencia, 2006, pp. 103-160.

Cabedo, V., Constitucionalismo y Derecho Indígena en América Latina, Editorial Universidad Politécnica de Valencia, Colección Amadís, Valencia, 2004.

Cabedo, V., La Jurisdicción Especial Indígena de Colombia y los Derechos Humanos, Valencia, 30 diciembre de 1998. http://www.alertanet.org/F2b-VCabedo.htm

Carmona, C., "Derecho y Violencia: reescrituras en torno al pluralismo jurídico", Revista de Derecho, Universidad Austral de Chile, Vol. XXII No 2, diciembre 2009, pp. 9-26.

Carnevalli, R., "El multiculturalismo: un desafío para el derecho penal moderno", Rev. Política criminal, $\mathrm{N}^{\circ}$ 3, 2007, www.politicacriminal.cl

Cassigoli y M. Sobarzo (eds.), Biopolíticas del Sur, Editorial Universidad Arcis, 2010.

Castro, M., Vergara, J. (eds.), Villegas, M., Albornoz, p. et al. Jurisprudencia Indígena. Cosmovisión y legislación, Programa de Antropología Jurídica Universidad de Chile. Ministerio de Justicia. Dic. 2009, p. 75.

Clavero, B., Chile: reforma constitucional cancelatoria de derechos indígenas, disponible en http:// clavero.derechosindigenas.org

Clavero, B., "Reconocimiento de Estados (no indígenas) por Pueblos (indígenas): Chile y Mapu, Caso y categoría”, en Giraudo, L. (ed.), Derechos, costumbres y jurisdicciones indígenas en la América Latina contemporánea, Cuadernos y Debates $\mathrm{N}^{\circ} 191$, Centro de Estudios Políticos y Constitucionales, Madrid, 2008, pp. 107-128.

Cóndor, E. (coord.), Rivera, E., Mendoza, M.A., Normas, procedimientos y sanciones de la justicia indígena en Perú. Comisión Andina de Juristas, Lima, 2010.

Correa, M., Molina, R., YÁnez, N., La reforma agraria y las tierras mapuches. Chile 1962-1975, Edit. LOM, Santiago de Chile. 2005.

Correa, P., Gundermann, K. et al., Mediación Intercultural. Estudio sobre conflictividad y modelos de intervención. Santiago de Chile: Ministerio de Justicia, Corporación Nacional indígena, Universidad Diego Portales, 2009.

Del Castillo, L., "Perú: entre la jurisdicción especial de las comunidades y la unidad del poder judicial”, en Giraudo, L. (Ed.), Derechos, costumbres y jurisdicciones indígenas en la América Latina contemporánea, pp. 243-264.

García. J.M., El estatuto indígena en la Constitución Guatemalteca de 1945. Edit. Serviprensa, Guatemala, 2010.

GiRAudo, L., "Entre rupturas y retornos: la nueva cuestión indígena en América Latina”, en Giraudo, L. (ed.), Ciudadanía y Derechos indígenas en América Latina: poblaciones, estados y orden internacional, Cuadernos y Debates No 179 , Centro de Estudios Políticos y Constitucionales, Madrid, 2007, pp. 7-57. 
Hurtado Pozo, J., "Derecho Penal y Diferencias culturales: el caso peruano”, en Borja, E. (coord.), Diversidad cultural: conflicto y derecho, Tirant Monografías, Valencia, 2006, pp. 373-388.

Instituto de la Defensa Pública Penal Guatemalteca. Proyecto Defensorías Indígenas. Peritajes culturales y su aplicación en la Administración de Justicia, Guatemala, 2009.

Instituto Nacional de Derechos Humanos, "Situación de los Derechos Humanos en Chile. Informe Anual 2011, Andros Impresores, Santiago, Chile, 2011.

KymlickA, W., Ciudadanía multicultural, Edit. Paidós: Estado y Sociedad. Barcelona, 2006.

LILlo, R. "El convenio 169 de la OIT y la defensa penal de indígenas". Minuta regional No 1/2010/ abril. Defensorías Regionales. Defensoría Penal Pública. Chile, 2010.

LondoÑo, H., "El fuero y la jurisdicción penal especial indígenas en Colombia". En Derecho Penal y pluralidad cultural, Anuario de Derecho Penal, 2006, pp. 153-210.

Medrano Ossio, J., Responsabilidad penal de los indígenas, Cuadernos Universidad autónoma Tomás Frías, Potosí, Bolivia, 1940.

Ministerio de Justicia y Derechos Humanos, Anteproyecto de Código Orgánico de Garantías Penales. La Constitucionalización del Derecho Penal. Publicación de la Serie Justicia y Derechos Humanos, Neoconstitucionalismo y Sociedad, V\&M Gráficas, Quito, Ecuador, 2009.

Modolell, J.L., "Breves consideraciones sobre la posible responsabilidad penal de sujetos pertenecientes a grupos culturalmente diferenciados (casos del indígena y costumbres de origen afroamericano), en Derecho Penal y Pluralidad Cultural, Anuario de Derecho Penal, 2006, pp. 273-286.

Molina, R., "La justicia comunitaria en Bolivia: cambios y continuidades, en Giraudo, L. (Ed.), Derechos, costumbres y jurisdicciones indígenas en la América Latina contemporánea, Cuadernos y Debates No 191, Centro de Estudios Políticos y Constitucionales, Madrid, 2008, pp. 96-126.

Nogueira, H. "Las constituciones y los tratados en materia de derechos humanos: América Latina y Chile", Ius et Praxis, año 6 No 2, 2002,pp. 229-279.

Paul Amry, R., "Defensa cultural y pueblos indígenas: propuestas para la actualización del debate", en Derecho Penal y pluralidad cultural. Anuario de Derecho pena,l 2006, pp. 73-100.

Silva Bascuñán, A., Tratado de Derecho Constitucional, Tomo IV. La Constitución de 1980, Bases de la institucionalidad. Nacionalidad y ciudadanía. Justicia Electoral, $2^{\mathrm{a}}$ edición, Editorial Jurídica de Chile, Santiago de Chile, 1997, p. 121.

Sieder, R., Flores, C., Autoridad, autonomía y derecho indígena en la Guatemala de posguerra. F \& G Editores, Casa Comal, Universidad Autónoma de Morelos, Guatemala, 2011.

Sotomayor, J. O., "La responsabilidad penal del indígena en Colombia. Entre el mundo real y un mundo posible". Jueces para la democracia, N²6, 1996, pp. 89-96.

Stavenhagen, R., Los pueblos originarios: el debate necesario, Fernández N. (comp.), CTA Ediciones, CLACSO, Buenos Aires, 2010.

Taylor, Ch., Gutmann, A., Habermas, J., El multiculturalismo y "la política del reconocimiento", FCE, $2^{a}$. edic. (español), México, 2009.

Tótoro, D., "Üxüf Xipay - El Despojo". Video Documental, Ceibo Producciones. $1^{\circ}$ Premio, Categoría Pueblos indígenas, Festival Internacional de Cine Documental "Contra el silencio todas las voces”, México, 2004., $1^{\circ}$ Premio, valor testimonial y Documental, VII Festival de Cine y Video de los Pueblos Indígenas, Stgo. Chile, 2004.

Touraine, A., ¿Podemos vivir juntos?, FCE, D.F. México, 1997.

Valenzuela, M., "Derechos de los pueblos indígenas en el contexto internacional, especialmente en lo relativo a los aspectos penales", en Revista de Estudios Criminológicos y Penitenciarios, $\mathrm{N}^{\circ}$ 6, Santiago de Chile, 2003, pp. 9-36.

Villavicencio, L., "Privatizando la diferencia: El liberalismo igualitario y el pluralismo cultural”, Revista de Derecho, Universidad Austral, Vol. XXIII, No 1, Julio 2010, pp. 37-57. 
VILlegas, M., "El mapuche como enemigo en el derecho penal: Consideraciones desde la biopolítica y el derecho penal del enemigo", en Portal Iberoamericano de las Ciencias Penales. Disponible en http//es.scribd.com

Villegas, M., Derecho Penal del enemigo y la criminalización del pueblo mapuche. Ediciones La Cátedra, 2009.

Villegas, M., Quintana, L., Meza-Lopehandía, M., Díaz, F., Jaque, I., Saavedra, S., El ejercicio de derechos como acto subversivo y la respuesta estatal: El Derecho Penal del Enemigo. Iniciativa interdisciplinaria en Conflicto Mapuche y Derecho Penal. Programa de investigación Domeyko. Subprograma sujetos y actores sociales. Universidad de Chile. Marzo 2010. Disponible en http/es.scribd.com

Wolkmer, C., "Pluralismo Jurídico: nuevo marco emancipatorio en América Latina". En García Villegas, M., Rodríguez, C. (eds.), Derecho y sociedad en América Latina: Un debate sobre los estudios jurídicos críticos, Ilsa, Universidad Nacional de Colombia, 2003, pp. 247 a 259.

ZAFFARONI, E. R., "Consideraciones acerca del reconocimiento del pluralismo cultural en la ley penal" y "Consideraciones previas para la elaboración de un Código penal para Bolivia". Parte General del Anteproyecto de Reforma al Código Penal de Bolivia, Conforme a la Resoluciones adoptadas en Santa Cruz de la Sierra (2008) y Buenos Aires (2008-2009). Disponible en www.cuestionpenal.blogspot.com

Zaffaroni, E.R., Alagia, A., Slokar, A., Derecho Penal. Parte General. Edit. Ediar, Buenos Aires, $2^{a}$ edición, 2002. 
